\title{
Right Inguinal Obstructed Littre's Hernia in a Child
}

\author{
Rattan KN'1, Bansal S², Arora I3, Dhamija A4, Tanwar M
}

${ }^{1}$ Dr. KN Rattan, MBBS, MD, Senior Professor \& Head, Department of Paediatric Surgery, ${ }^{2}$ Dr. Shruti Bansal, MBBS, MD Resident, Department of Pathology, ${ }^{3} \mathrm{Dr}$. Ishani Arora, MBBS. MD Resident, Department of Paediatrics. ${ }^{4} \mathrm{Dr}$. Aastha Dhamija, MBBS, MD Resident, Department of Pathology, ${ }^{5} \mathrm{Dr}$. Manpreet Tanwar, MBBS, MD Resident, Department of Pathology. All from the Pt. B.D. Sharma University of Health Sciences, PGIMS, Rohtak, Haryana.

\section{Address for correspondence:}

Dr. Shruti Bansal

E-mail: shruti.b.bansal3@gmail.com

\section{How to cite}

Rattan KN, Bansal S, Arora I, Dhamija A, Tanwar M. Right Inguinal Obstructed Littre's Hernia in a Child. J Nepal Paediatr Soc 2016;36(3):300-302

doi: http://dx.doi.org/10.3126/jnps.v36i3.15207

This work is licensed under a Creative Commons Attribution 3.0 License.

\begin{abstract}
Littre's hernia, in which the hernia sac contains a Meckel's diverticulum, is extremely uncommon in paediatric population. We are reporting a case of Littre hernia in a 4.5 year old male child who presented with an irreducible mass in right inguinal region. The diagnosis was made peroperatively. The patient was successfully managed by diverticulectomy and herniotomy and is doing well in follow up.
\end{abstract}

Key words: Littres, Hernia, Meckel's diverticulum, Children

\section{Introduction}

Littre's hernia (LH)is the protrusion of Meckel diverticulum (MD) through a potential abdominal opening with a container sac. It was originally defined as "the presence of a Meckel's diverticulum in any hernial sac" by Reinke in $1841^{1}$. The entity was first described by Alexis Littre in 1700 as "ileal diverticula in the inguinal hernia". However, the concept of "Littre's hernia" was improved when Johann Friedrich Meckel in 1809 defined the true congenital diverticulum of the gut, which is now named after him².

Littre's hernia is reported for inguinal, umbilical, femoral, ventral, sciatic and lumbar regionsand is generally difficult to differentiate from other types of hernia until complications arise. It is a rare and accidental finding at any age. In adults, the incidence is about $4-10 \%$ but the presentation is quite rare in childhood and the true incidence is unknown. In this case report, a case of 4.5 year old male child who presented with irreducible mass in right inguinal region and diagnosed intraoperatively as Littre's hernia is reported.

\section{The Case}

A four and a half years age, male child was brought to department of paediatric surgery with complaints of swelling in right inguinal region since one month. The swelling was associated with pain in the abdomen and vomiting. There was however no episode of gastrointestinal bleeding.

On examination, an irreducible painless swelling was observed in right inguinal region. The overlying skin was stretched and shiny. The abdomen was soft and mildly distended.Haemoglobin, bleeding time and clotting time were normal. Serum electrolytes and renal 
function tests and other biochemical investigations were also within normal limits. Plain abdominal radiograph demonstrated few air fluid levels. Ultrasonography revealed small gut in the sac with minimal fluid.

The child waskept NPO. Intravenous fluids and antibiotics were started. A diagnosis of obstructed inguinal hernia was made and the child was scheduled for emergency surgery.Through right inguinal incision, inguinal canal was opened and cord was identified along with sac. The sac contained gut. Sac was opened and the contents of this sac was MD along with loop of ileum (Figure 1). The tip of MD was found to be adherent to the base of the sac, thereby preventing complete reduction. Diverticulectomy was done. Gut was closed in single layer transversely (Figure 2). Herniotomy was done. Post-operative period was uneventful.

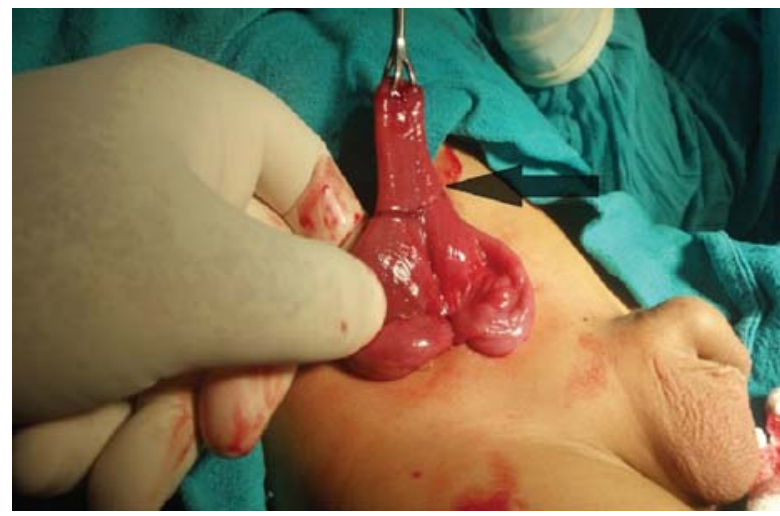

Fig 1: Photograph showing Meckels diverticulum with loop of ileum.

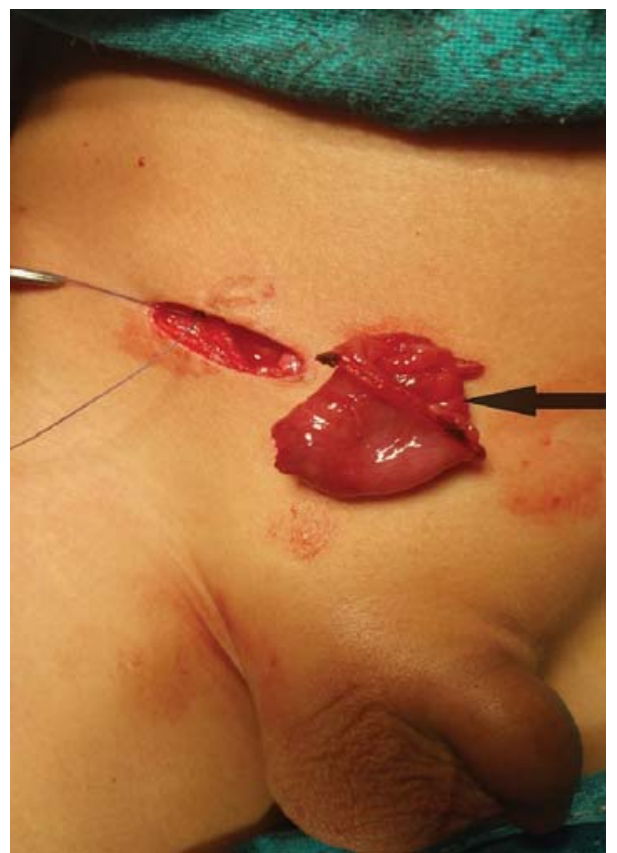

Fig 2: MD placed along with incisional site

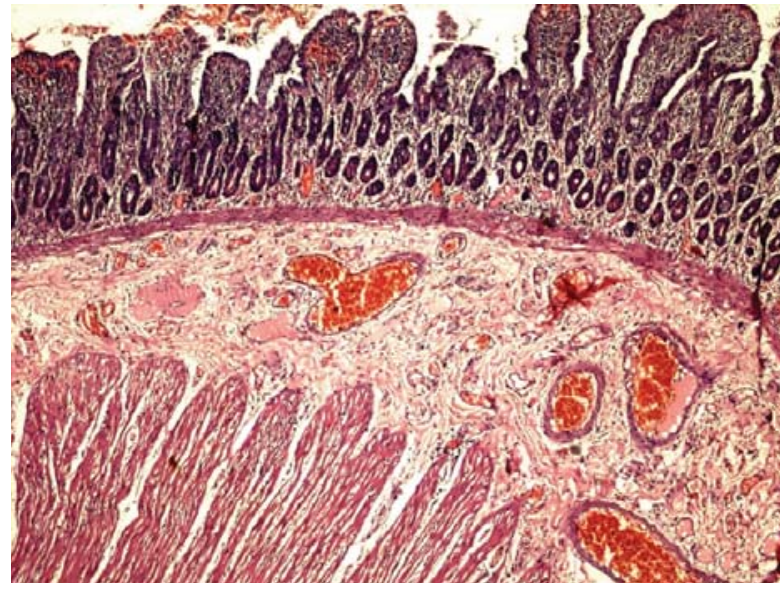

Fig 3: Photomicrograph showing histopathology of MD revealing lining of small intestinal mucosa. ((Hematoxylin $\&$ eosin stain, $\times 40$ )

The surgically resected specimen was sent forhistopathological examination. Histopathology was suggestive of meckel's diverticulumrevealing lining of small intestinal mucosa with marked congestion and non-specific inflammation in the wall (Figure 3). However, it did not reveal any heterotopic mucosa.

Oral feeds were started 48 hours after the surgery. The child did well without any complications and was discharged home on the seventh postoperative day and is doing well in follow up.

\section{Discussion}

Meckel diverticulum is the most common congenital anomaly of the gastrointestinal tract, occurring in 2-3\% of the population ${ }^{3}$. Incomplete closure and absorption of the omphalomesenteric duct leads to the formation of the Meckel diverticulum containing all layers of the gut wall ${ }^{4}$. It is two inches in length, located two feet from the ileocecal junction and often contains heterotopic gastric and pancreatic mucosa and less commonly duodenal, colonic or biliary mucosa. It is a true diverticulum found in the anti-mesenteric border. It lies free in the peritoneal cavity and has therefore tendency to move towards any weak abdominal opening. Once it enters the sac, it adheres to the base of sac resulting in obstruction. Umbilical protrusion is more common than the other hernia sites ${ }^{2}$.

MD commonly complicates before the age of two years and due to this reason, it is accepted as a childhood disease.The common complications are obstruction of the small intestine, hemorrhage from ectopic gastric ulceration and diverticulitis. Bleeding is the most common complication, especially occurring in children and typically presenting as hematochezia. 
LHis however an unusual complication of $\mathrm{MD}^{5}$. It is a rare finding in adults with an incidence of about $4-10 \%$ and still rarer in children ${ }^{2}$. The period of infancy seems to be the most risky one as the chance of $\mathrm{LH}$ is probably attributed to the tendency of incarceration in this age group. It predominantly affects the male gender and is more common on the right side than the left.

Review of literature has revealed 69 cases of $\mathrm{LH}$ in the childhood period in case reports and case series from the beginning of the $20^{\text {th }}$ century till date. Fifty one of these patients presented with LH in the infancy period and the vast majority of them were males. This review revealed that umbilicus is the commonest site (64-85\%), with the omphalomesenteric duct being a component of fetal umbilicus and inguinal region is the second commonest site, with a prevalence of $15-33.8 \%$ in all age groups.Also it was found that not solely umbilical hernias but any kind of persisting umbilical openings including umbilical cord hernias, exomphalos minor and major are the most common sites for LH.The complication rate of $\mathrm{LH}$ in this series was about $38.5 \%$ and the presence of heterotopic mucosa was found to be a rare finding ${ }^{6}$.

Messina et al reported two cases of Littre's hernia in newborn infants which were treated in first 20 days of $\mathrm{life}^{7}$. A case was reported by Pampal et al in a three year old boy who presented with right-sided incarcerated inguinal hernia for which elective herniorrhaphy was performed $^{6}$. Pujar et al reported a case of Littre's hernia in a two year old male child for which resection of MD with ileal segment was done and the continuity was

\section{References}

1. Sinha F. Bowel obstruction due to Littre hernia: CT diagnosis. Abdom Imaging 2005;30:682-4.

2. Skandalakis PN, Zoras O, Skandalakis JE, Mirilas P. Littre hernia: Surgical anatomy, embryology, and technique of repair. Am Surg2006;72:238-43.

3. Moore TC. Omhalomesenteric duct malformations. Semin Pediatr Surg 1996;5:116-23.

4. Lauschke $H$, Kaminski $M$, Stratmann $H$, Hirner A. Littre's herniaclinical aspects and review of the history. Der Chirurg 1999;70:953-6.

5. Fa-Si-Oen PR, Roumen RM, Croiset van Uchelen FA. Complications and management of meckel's diverticulum-a review. Eur J Surg 1999;165:674-8. restored by ileoileal anastomosis ${ }^{8}$.

Symptoms of Littre hernia consists of vague, crampy abdominal pain, dyspepsia, and occasional anorexia with malaise. The preoperative diagnosis of a $\mathrm{LH}$ is difficult to establish. Findings like incomplete manual reduction of an incarcerated hernia, fecal fistulas in a hernia sac, and previous history of rectal bleeding should alert the clinician about a $\mathrm{LH}^{9}$. In case of mechanical small intestinal obstruction plain abdominal radiographs may demonstrate air fluid level. However,the diagnosis is generally not possible with computerized tomography unless the diverticulum is visualized.

In the management of a $\mathrm{LH}, \mathrm{MD}$ must be resected. The accepted treatment is wedge resection of the diverticulum and repair of the ileum from within the $\mathrm{sac}^{10}$. If there is an edema or inflammation at the base of the diverticulum, resection and anastomosis of a segment of the ileum may be necessaryto prevent postoperative stricture of the resected segment.

\section{Conclusion}

Meckel diverticulum may be found in any type of hernia.Littre's hernia without an incarceration is very rare in pediatric age group and may cause diagnosis and treatment difficulties for surgeons. In treatment of uncomplicated Littre hernia, wedge resection of Meckel diverticulum should be donethrough a groin incision avoiding a formal laparotomy and it is better to perform resection and anostomosis of ileal segment in these patients to prevent postoperative ileal stricture.

6. Pampal A, Aksakal ED. Littre hernia in childhood: A case report with a brief review of the literature.Afr $J$ Paediatr Surg 2011;8:221-4.

7. Messina M, Ferrucci E, Meucci D, Maggio GD, Molinaro F, Buonocore G. Littres hernia in newborn infants: report of two cases.Pediatr Surg Int 2005;21:485-7.

8. Pujar VC, Joshi SS. Littré hernia: A surgical surprise. J Sci Soc. 2015;42:198-200.

9. St-Vil D, Brandt ML, Panic S, Bensoussan AL, Blanchard H. Meckel's diverticulum in children: A 20year review. J Pediatr Surg 1991;26:1289-92.

10. Ravikumar KK, Khope SS, Ganapathi BP. Littre's hernia in a child-an operative surprise(a case report). $J$ Postgrad Med 1989;35:112-3. 